\title{
RESEARCH
}

Open Access

\section{Clinical and neurophysiological correlation in axonal and demyelinating polyneuropathy}

Kamel Mahmoud Ali Hewedi', Mahmoud Abdelmoety Monzer ${ }^{1}$, Khaled Mohammad Sobh', Mohammad Abdelhady M. Aboelmakarem', Amir Abdelghaffar Mohammady", Mahmoud Mohamad Hasan', Mohammad Fathi Abdulsalam ${ }^{1}$ and Suzette Ibrahim Ibrahim Ibrahim Helal ${ }^{2^{*}}$ (D)

\begin{abstract}
Background: The neurophysiological examination provides valuable pathophysiological information for the diagnosis, prognosis, and therapy of patients with polyneuropathy (Fuglsang- Fredriksen A., Pugdahl K. Clin Neurophysilogy 122: $440-455,2011)$. Nerve conduction study (NCS) is the most objective and reliable measure of peripheral nerve function and is considered the gold standard for the diagnosis of most neuropathies.

Aim of the study: To evaluate the clinical usefulness of nerve conduction study (NCS) in the differentiation between axonal and demyelinating polyneuropathies.

Methods: In the present study, 125 patients with polyneuropathy were studied ranging age from 9 to 79 years. Thirtysix patients were classified as axonal polyneuropathy, 23 patients as demyelinating, and 9 as mixed, while 57 patients were classified as neuropathic. Nerve conduction study (NCS) and electromyography (EMG) were performed using Nihon Kochden electromyography machine with surface recording and stimulating electrodes.

Results: There is statistically significant linear correlation between reduction in sensory nerve action potential (SNAP) amplitude and decrease in sensory conduction velocity (SCV) of median and ulnar nerves. Also, there is statistically significant inverse correlation between reduction in compound motor action potential (CMAP) amplitude and increase in distal motor latency (DML). There is statistically significant linear correlation between reduction in compound motor action potential (CMAP) amplitude and decrease in motor conduction velocity (MCV). There is statistically significant linear correlation between reduction in compound motor action potential (CMAP) amplitude and decreased grade of power in both axonal and demyelinating polyneuropathy; statistically significant linear correlation was found between decrease in conduction velocity and decrease in grade of power.
\end{abstract}

Conclusion: The present study demonstrates significant correlation between amplitude reduction and conduction slowing in demyelinating as well as axonal polyneuropathy.

Keywords: Polyneuropathy, Demyelinating, Axonal, Motor, Sensory

\footnotetext{
* Correspondence: suzettehelal@yahoo.com

This work done in Al-Azhar University, university hospital.

2Department of Research of Child with Special Needs, National Research

Centre, Cairo, Egypt

Full list of author information is available at the end of the article
}

\section{Springer Open}

(c) The Author(s). 2020 Open Access This article is licensed under a Creative Commons Attribution 4.0 International License, which permits use, sharing, adaptation, distribution and reproduction in any medium or format, as long as you give appropriate credit to the original author(s) and the source, provide a link to the Creative Commons licence, and indicate if changes were made. The images or other third party material in this article are included in the article's Creative Commons licence, unless indicated otherwise in a credit line to the material. If material is not included in the article's Creative Commons licence and your intended use is not permitted by statutory regulation or exceeds the permitted use, you will need to obtain permission directly from the copyright holder. To view a copy of this licence, visit http://creativecommons.org/licenses/by/4.0/. 


\section{Introduction}

Polyneuropathy is a common disorder with heterogenic clinical presentation and many different etiologies. Neurophysiological examination plays an important role in defining the presence of a polyneuropathy and in terms of delineating the underlying pathophysiological process (i.e., primary axonal loss vs primary demyelination) (Mygland 2007).

\section{Aim of the work}

The aims of the work are the following: to evaluate the clinical usefulness of conduction slowing and CMAP or SNAP amplitude reduction in the differentiation between axonal and demyelinating polyneuropathies and to correlate the neurophysiological results with the clinical findings in all patients.

\section{Patients and methods}

One hundred and twenty-five patients with symptoms and signs of polyneuropathy, 78 males (62.4\%) and $47 \mathrm{fe}-$ males (37.6\%), were studied ranging in age from 9 to 79 years (44.75 \pm 17.66$)$. Patients were questioned for sensory, motor, and autonomic symptoms. A clinical history and full neurological examination were obtained and incorporated when necessary from the patient's file, as well as all laboratory investigations. The patients were classified according to criteria proposed by the ESTEEM group (Tankisi et al. 2005).

\section{Control group}

The control group included 30 healthy asymptomatic individuals, 19 males (63.3\%) and 11 females (36.7\%), with no history of diabetes or other systemic diseases with mean age $39.07 \pm 9.42$. They showed normal neurological examination.

\section{Methods}

All electrophysiological studies were performed using Nihon Kochden electromyography machine with surface recording and stimulating electrodes. Nerve conduction studies were carried out at $33{ }^{\circ} \mathrm{C}$ room temperature (Agarwal et al. 2008). Sensory studies were performed in all patients and controls using surface electrodes for stimulation and recording for median, ulnar, and sural nerves. Motor studies were performed in all patients and controls using surface electrodes for stimulation and recording. CMAPs were recorded with surface electrodes on the abductor pollicis brevis (APB) muscle for the median nerve, abductor digiti minimi (ADM) muscle for the ulnar nerve, extensor digitorum brevis (EDB) muscle for the peroneal nerve, and abductor hallucis (AH) muscle for the tibial nerve (Weiss et al. 2004).

\section{Electromyography (EMG)}

Standard needle electromyography (EMG) was performed using sterile concentric needle electrodes. For spontaneous activity assessments are the following: analysis of the duration and amplitude and incidence of polyphasic potentials (> 4 phases) of motor unit action potentials (Brown and Bolton 1993).

\section{Statistical analysis}

Statistical analysis of the present study was conducted using the mean, standard error, correlation analysis, and chi-square. All statistical analyses were performed using SPSS 19 for Windows.

\section{Results}

The study included one hundred and twenty-five cases of polyneuropathy, 78 males (62.4\%) and 47 females (37.6\%), who were classified according to the criteria proposed by the ESTEEM group (Tankisi et al. 2005). The mean age of the subjects was $44.75 \pm 17.66$ years. Cases were divided into 36 patients with axonal polyneuropathy, 23 patients with demyelinating polyneuropathy, and 9 patients with mixed polyneuropathy, while 57 patients were classified as neuropathic (Table 1). Clinical findings in patients with axonal and demyelinating polyneuropathies are shown in Table 2. The number of analyzed nerve segments with the total number of examined segments and the number of absent responses are indicated in parentheses (Table 3). There is statistically significant linear correlation between reduction in

Table 1 Etiology of cases with axonal and demyelinating polyneuropathies

Number of cases

\begin{tabular}{lr}
\hline Axonal polyneuropathies & 12 \\
Unknown & 9 \\
Diabetic neuropathy & 7 \\
Axonal GBS & 3 \\
Hereditary neuropathy & 3 \\
Uremic neuropathy & 1 \\
Vasculitic neuropathy & 1 \\
Sarcoid neuropathy & $\mathbf{3 6}$ \\
Total &
\end{tabular}

12

9

7

3

3

1

Demyelinating polyneuropathies

$\begin{array}{ll}\text { CIDP } & 10 \\ \text { Demyelinating GBS } & 6 \\ \text { Hereditary neuropathy } & 3 \\ \text { Unknown } & 3 \\ \text { MMN } & 1 \\ \text { Total } & 23\end{array}$

GBS Guillain-Barre syndrome, CIDP chronic inflammatory demyelinating polyneuropathy, $M M N$ multifocal motor neuropathy 
Table 2 Clinical findings in patients with axonal and demyelinating polyneuropathies

\begin{tabular}{|c|c|c|}
\hline & $\begin{array}{l}\text { Axonal } \\
\text { polyneuropathy }\end{array}$ & $\begin{array}{l}\text { Demyelinating } \\
\text { polyneuropathy }\end{array}$ \\
\hline Age (years) & $46.5 \pm 17.3$ & $42 \pm 18.3$ \\
\hline Sex (male/female) & 20/16 & $14 / 9$ \\
\hline \multicolumn{3}{|l|}{ Muscle wasting, $n(\%)$} \\
\hline Upper limbs & $9(25 \%)$ & $6(25 \%)$ \\
\hline Lower limbs & $15(41.7 \%)$ & $7(30.4 \%)$ \\
\hline \multicolumn{3}{|l|}{ Motor weakness, $n(\%)$} \\
\hline Facial & $9(25 \%)$ & $13(56.5 \%)$ \\
\hline Bulbar & $4(11.1 \%)$ & $4(17.4 \%)$ \\
\hline Upper limbs & $28(77.8 \%)$ & $21(91.3 \%)$ \\
\hline Lower limbs & $36(100 \%)$ & $23(100 \%)$ \\
\hline \multicolumn{3}{|l|}{ Hypo/areflexia, $n$ (\%) } \\
\hline Upper limbs & $24(66.7 \%)$ & $21(91.3 \%)$ \\
\hline Lower limbs & $36(100 \%)$ & $23(100 \%)$ \\
\hline \multicolumn{3}{|c|}{ Distal loss/reduction of pin prick sensation, $n(\%)$} \\
\hline Upper limbs & $24(66.7 \%)$ & $18(78.3 \%)$ \\
\hline Lower limbs & $34(94.4 \%)$ & $22(95.7 \%)$ \\
\hline $\begin{array}{l}\text { Loss/reduction of vibration sense at } \\
\text { ankles (medial malleolus), } n(\%)\end{array}$ & $34(94.4 \%)$ & $22(95.7 \%)$ \\
\hline
\end{tabular}

SNAP amplitude and decrease in sensory CV of median and ulnar nerves while no significant correlation was found between reduction in SNAP amplitude and sensory $\mathrm{CV}$ of sural nerve in both axonal and demyelinating polyneuropathy (Table 4). There is statistically significant inverse correlation between reduction in CMAP amplitude and increase in DML of median, ulnar, and tibial nerves in both axonal and demyelinating polyneuropathy, while in peroneal nerve, significant inverse correlation was found in axonal but not in demyelinating polyneuropathy (Table 5). There is statistically significant linear correlation between reduction in CMAP amplitude and decrease in motor $\mathrm{CV}$ of median, ulnar, peroneal, and tibial nerves in axonal polyneuropathy while in demyelinating polyneuropathy, significant linear correlation was found in median, ulnar, and tibial nerves

Table 3 Analyzed nerve conduction studies

\begin{tabular}{llllll}
\hline Nerve & \multicolumn{2}{l}{ Axonal } & & & \multicolumn{2}{l}{ Demyelinating } \\
\cline { 2 - 3 } \cline { 6 - 6 } & Motor $(\boldsymbol{n})$ & Sensory $(\boldsymbol{n})$ & & Motor $(\boldsymbol{n})$ & Sensory $(\boldsymbol{n})$ \\
\hline Median & $16(36 / 0)$ & $11(36 / 12)$ & & $19(23 / 0)$ & $10(23 / 7)$ \\
Ulnar & $26(36 / 0)$ & $10(36 / 12)$ & & $18(23 / 0)$ & $9(23 / 6)$ \\
Peroneal & $24(36 / 8)$ & & $13(23 / 7)$ & \\
Tibial & $23(36 / 6)$ & & $13(23 / 3)$ & \\
Sural & & $8(36 / 25)$ & & $5(23 / 16)$ \\
Total & 89 & 29 & 63 & 24 \\
\hline
\end{tabular}

Table 4 The correlation between reduction in SNAP amplitude and decrease in CV of sensory nerves in axonal and demyelinating polyneuropathy

\begin{tabular}{lll}
\hline Sensory nerves & $\boldsymbol{r}$ & $\boldsymbol{p}$ value \\
\hline Axonal polyneuropathy & & \\
Median nerve & 0.784 & $0.004^{*}$ \\
Ulnar nerve & 0.849 & $0.002^{*}$ \\
Sural nerve & 0.270 & 0.518 \\
Demyelinating polyneuropathy & & \\
Median nerve & 0.734 & $0.016^{*}$ \\
Ulnar nerve & 0.844 & $0.004^{*}$ \\
$\quad$ Sural nerve & 0.285 & 0.642 \\
\hline *Highly significant & &
\end{tabular}

* Highly significant

but not in peroneal nerve (Table 6). There is no significant correlation between distal motor latency and grade of power (MRC grade) in median, ulnar, and peroneal nerves while in tibial nerve in demyelinating polyneuropathy, statistically significant inverse correlation was found between prolongation of distal motor latency and decrease of grade of power (Table 7). There is statistically significant linear correlation between reduction in CMAP amplitude and decreased grade of power (MRC grade) in median, ulnar, peroneal, and tibial nerves in both axonal and demyelinating polyneuropathy (Table 8). There is no significant correlation between conduction velocity and grade of power (MRC grade) in median, peroneal, and tibial nerves while in ulnar nerve in demyelinating polyneuropathy, statistically significant linear correlation was found between decrease in conduction velocity and decrease in grade of power (Table 9).

\section{Discussion}

The results in the present study showed a linear correlation between amplitude reduction and conduction

Table 5 The correlation between reduction in CMAP amplitude and increase in distal motor latency of motor nerves in axonal and demyelinating polyneuropathy

\begin{tabular}{lll}
\hline Motor nerves & $\boldsymbol{r}$ & $\boldsymbol{p}$ value \\
\hline Axonal polyneuropathy & -0.761 & \\
Median nerve & -0.612 & $0.001^{*}$ \\
Ulnar nerve & -0.677 & $0.001^{*}$ \\
Peroneal nerve & -0.812 & $0.000^{*}$ \\
Tibial nerve & & $0.000^{*}$ \\
Demyelinating polyneuropathy & -0.640 & \\
Median nerve & -0.521 & $0.003^{*}$ \\
Ulnar nerve & -0.300 & $0.027^{*}$ \\
Peroneal nerve & -0.738 & 0.297 \\
Tibial nerve & & $0.002^{*}$ \\
\hline
\end{tabular}

* Highly significant 
Table 6 The correlation between reduction in CMAP amplitude and decrease in conduction velocity of motor nerves in axonal and demyelinating polyneuropathy

\begin{tabular}{lll}
\hline Motor nerves & $\boldsymbol{r}$ & $\boldsymbol{p}$ value \\
\hline Axonal polyneuropathy & & \\
$\quad$ Median nerve & 0.709 & $0.002^{*}$ \\
Ulnar nerve & 0.605 & $0.001^{*}$ \\
Peroneal nerve & 0.664 & $0.000^{*}$ \\
$\quad$ Tibial nerve & 0.666 & $0.001^{*}$ \\
Demyelinating polyneuropathy & & \\
Median nerve & 0.637 & $0.003^{*}$ \\
Ulnar nerve & 0.761 & $0.000^{*}$ \\
Peroneal nerve & 0.178 & 0.541 \\
Tibial nerve & 0.584 & $0.036^{*}$ \\
\hline * Highly significant & &
\end{tabular}

slowing in the majority of motor nerves and also sensory nerves in both groups of axonal and demyelinating polyneuropathy.

\section{Axonal polyneuropathies}

The findings in the present study confirm the results of the study presented by Tankisi et al. (2007) who found the SNAP amplitude reduction to be linearly correlated with decrease in sensory $\mathrm{CV}$ in axonal polyneuropathy. The correlation in motor nerves for axonal polyneuropathy in the present study confirmed the mentioned study compared nerve conduction measures in axonal and demyelinating polyneuropathies.

\section{Demyelinating polyneuropathies}

In the study presented here, a linear correlation between reductions in sensory nerve action potential amplitude and decrease in sensory conduction velocity was found

Table 7 Correlations between distal motor latency in each tested nerve and the strength of their muscular counterparts (MRC grade) in axonal and demyelinating polyneuropathy

\begin{tabular}{lll}
\hline Nerve & $\boldsymbol{r}$ & $\boldsymbol{p}$ value \\
\hline Axonal polyneuropathy & & \\
Median nerve & 0.057 & 0.739 \\
Ulnar nerve & 0.106 & 0.538 \\
Peroneal nerve & -0.214 & 0.273 \\
Tibial nerve & -0.087 & 0.647 \\
Demyelinating polyneuropathy & & \\
Median nerve & -0.381 & 0.073 \\
Ulnar nerve & -0.344 & 0.108 \\
Peroneal nerve & -0.327 & 0.217 \\
Tibial nerve & -0.571 & $0.009^{*}$ \\
\hline * Highly significant & &
\end{tabular}

* Highly significant
Table 8 Correlations between compound muscle action potential amplitude in each tested nerve and the strength of their muscular counterparts (MRC grade) in axonal and demyelinating polyneuropathy

\begin{tabular}{lll}
\hline Nerve & $\boldsymbol{r}$ & $\boldsymbol{p}$ value \\
\hline Axonal polyneuropathy & & \\
$\quad$ Median nerve & 0.621 & $0.000^{*}$ \\
Ulnar nerve & 0.688 & $0.000^{*}$ \\
Peroneal nerve & 0.376 & $0.049^{*}$ \\
Tibial nerve & 0.513 & $0.004^{*}$ \\
Demyelinating polyneuropathy & & \\
Median nerve & 0.522 & $0.011^{*}$ \\
Ulnar nerve & 0.436 & $0.038^{*}$ \\
Peroneal nerve & 0.830 & $0.000^{*}$ \\
Tibial nerve & 0.830 & $0.000^{*}$ \\
\hline
\end{tabular}

* Highly significant

in most nerves in patients with demyelinating polyneuropathies. These findings are going with that of Krarup and Trojaborg (1996) who reported slowing of sensory conduction in association with markedly decreased SNAP amplitude in patients with chronic acquired demyelinating polyneuropathy. These findings also confirm the study by Tankisi et al. (2007) who found the slowing of sensory conduction to be linearly correlated with reduction in SNAP amplitude in patients with demyelinating polyneuropathies of different etiologies. In motor nerves, the linear correlation between CMAP amplitude reduction and conduction slowing found in the present study was in agreement with the findings in the aforementioned studies by Krarup and Trojaborg (1996) and Tankisi et al. (2007), while Wilson and colleagues did not find CMAP amplitude and motor $\mathrm{CV}$ to be correlated in chronic inflammatory

Table 9 Correlations between conduction velocity in each tested nerve and the strength of their muscular counterparts (MRC grade) in axonal and demyelinating polyneuropathy

\begin{tabular}{lll}
\hline Nerve & $\boldsymbol{r}$ & $\boldsymbol{p}$ value \\
\hline Axonal polyneuropathy & & \\
Median nerve & 0.250 & 0.141 \\
Ulnar nerve & 0.009 & 0.960 \\
Peroneal nerve & 0.366 & 0.055 \\
Tibial nerve & 0.136 & 0.482 \\
Demyelinating polyneuropathy & & \\
Median nerve & 0.304 & 0.158 \\
Ulnar nerve & 0.460 & $0.027^{*}$ \\
Peroneal nerve & 0.329 & 0.213 \\
$\quad$ Tibial nerve & 0.241 & 0.307 \\
\hline * Highly significant & &
\end{tabular}


demyelinating polyneuropathy (CIDP) (Wilson et al. 1998). Correlating the degree of weakness with nerve conduction parameters in the present study aimed at assessment of electro-clinical correlations in an attempt to find the potential parameters that could represent adequate biomarkers of disease activity. The results showed significant linear correlation between reduction in CMAP amplitude of median, ulnar, peroneal, and tibial nerves and decreased grade of power (MRC grade) in their muscular counterparts in both axonal as well as demyelinating polyneuropathy, whereas prolongation of DML correlated with decrease of grade of power only in tibial nerve and conduction velocity correlated with grade of power only in ulnar nerve in demyelinating polyneuropathy. These findings support earlier studies that found the degree of weakness to be only consistently correlated with CMAP amplitudes in chronic inflammatory demyelinating polyneuropathy by Rajaballya and Narasimhan (2011), multifocal motor neuropathy by Feasby et al. (1985), and in demyelinating CharcotMarie-Tooth disease by Kim et al. (2012). The results of the present study as regards the relationship between muscle weakness and decreased distal CMAP amplitude and the presence of needle electromyographic findings compatible with axonal loss in demyelinating polyneuropathy, in addition to previous studies, indicate that pathogenic mechanisms leading to axonal degeneration may play an important role in the outcome of the neurological deficit in patients with demyelinating neuropathies.

\section{Summary and conclusions}

The present study demonstrates significant correlation between amplitude reduction and conduction slowing in demyelinating as well as axonal polyneuropathy, and therefore, this correlation does not seem to be useful in revealing the primary pathophysiology of a polyneuropathy in the clinical routine at present. Decrease in CV, increase in DML, increase in F-wave latency, conduction block, and temporal dispersion should mainly be considered. Analysis of EMG findings in the present study showed no difference between axonal and demyelinating polyneuropathies as regards spontaneous activity assessment, interference pattern analysis, or motor unit action potential analysis indicating that in the differentiation of axonal and demyelinating pathologies, the value of needle EMG may be limited. The degree of muscle weakness was found to be only consistently correlated with CMAP amplitudes but not with DML or CV suggesting that CMAP amplitude can be used as a clinically relevant biomarker of disease activity in both axonal as well as demyelinating polyneuropathy. The relationship between muscle weakness and decreased CMAP amplitude and the presence of needle electromyographic findings compatible with axonal loss in demyelinating polyneuropathy indicate that secondary axonal degeneration may play an important role in the outcome in patients with demyelinating neuropathies.

\section{Abbreviations}

ADM: Abductor digiti minimi; AH: Abductor hallucis; APB: Abductor polices breves; CIDP: Chronic inflammatory demyelinating polyneuropathy; CMAP: Compound motor action potential; CV: Conduction velocity: DML: Distal motor latency; EDB: Extensor digitorum brevis;

EMG: Electromyography; ESTEEM: European standardized telemetric tools to evaluate electrodiagnostic methods; GBS: Guillain-Barre syndrome; MMN: Multifocal motor neuropathy; MCV: Motor conduction velocity; NCS: Nerve conduction study; SCV: Sensory conduction velocity; SNAP: Sensory nerve action potential

\section{Acknowledgements}

I want to express my genuine gratitude to all my professors and colleagues at the Department of Neurology, Al Azhar University, for their consideration and constant support that help me endure hardships.

\section{Authors' contributions}

$\mathrm{KH}$ carried out the work and responsible for methodology. MM carried out the analysis of nerve conduction and electrophysiological data. KS participated in the sequence alignment and drafted the manuscript. MA participated in the design of the study and performed the statistical analysis. AM statistical analysis; $\mathrm{MH}$ participated in its design and coordination and helped to draft the manuscript. MF carried out the procedure of nerve conduction study and electromyography; $\mathrm{SH}$ conceived the study and participated in its design and coordination and helped to draft the manuscript. All authors read and approved the final manuscript.

\section{Funding}

No financial grand

\section{Availability of data and materials}

All data generated or analyzed during this study are included in this published article [and its supplementary information files].

Ethics approval and consent to participate

We confirm that we have read the journal's position on issues involved in ethical publication and affirm that this report is consistent with those guidelines. This paper approved from al Al-Azhar ethical committee.

Consent for publication

My manuscript do not contains any individual person's data.

\section{Competing interests}

The authors declare that they have no competing interests.

\section{Author details}

${ }^{1}$ Faculty of Medicine, Al-Azhar University for boys, Cairo, Egypt. ${ }^{2}$ Department of Research of Child with Special Needs, National Research Centre, Cairo, Egypt.

Received: 4 June 2019 Accepted: 3 June 2020

Published online: 17 June 2020

\footnotetext{
References

Agarwal V, Singh R, Wiclaf, Chauhan S (2008) A clinical, electrophysiological, and pathological study of neuropathy in rheumatoid arthritis. ClinRheumatol 27: $841-844$

Brown W, Bolton C (1993) Clinical electromyography. Butterworth-Heinemann, Boston

Feasby T, Brown W, Gilbert J (1985) The pathological basis of conduction block in human neuropathies. J Neurol Neurosurg Psychiatry 48:239-244

Kim Y, Chung H, Park K (2012) Comparison between clinical disabilities and electrophysiological values in Charcot-Marie-Tooth 1A patients with PMP22 duplication. J Clin Neurol 8:139-145
} 
Krarup C, Trojaborg W (1996) Sensory pathophysiology in chronic acquired demyelinating neuropathy. Brain 119(Pt. 1):257-270

Mygland A (2007) Approach to the patient with chronic polyneuropathy. Acta Neurol Scand 115(Suppl. 187):15-21

Rajaballya Y, Narasimhan M (2011) Distribution, clinical correlates and significance of axonal loss and demyelination in chronic inflammatory demyelinating polyneuropathy. Eur I Neurol 18:293-299

Tankisi H, Pugdahl K, Fuglsang A (2005) Pathophysiology inferred from electrodiagnostic nerve tests and classification of polyneuropathies. Suggested guidelines. Clin Neurophysiol 116:1571-1580

Tankisi H, Pugdahl K, Johnsen B (2007) Correlations of nerve conduction measures in axonal and demyelinating polyneuropathies. Clin Neurophysiol $118: 2383-2392$

Weiss L, Silver J, Weiss J (2004) Easy EMG:a guide to performing nerve conduction studies and electromyography. Butterworth- Heinemann, Edinburgh

Wilson J, Stittsworth J, Kadir A (1998) Conduction velocity versus amplitude analysis: evidence for demyelination in diabetic neuropathy. Muscle Nerve 21:1228-1230

\section{Publisher's Note}

Springer Nature remains neutral with regard to jurisdictional claims in published maps and institutional affiliations.

\section{Submit your manuscript to a SpringerOpen ${ }^{\circ}$ journal and benefit from:}

- Convenient online submission

- Rigorous peer review

- Open access: articles freely available online

- High visibility within the field

- Retaining the copyright to your article

Submit your next manuscript at $\boldsymbol{\nabla}$ springeropen.com 